\title{
Knowledge and risk perceptions of Israelis towards combustible cigarettes: the need for immediate remedial action
}

\author{
Laura J. Rosen ${ }^{1,2^{*}}$ D, David A. Rier ${ }^{3}$, Robert Schwartz ${ }^{4}$, Michal Talitman ${ }^{1,5}$ and Lior Zwanziger ${ }^{6}$
}

\begin{abstract}
Background: Devastation from the tobacco epidemic continues, with strong government tobacco control policy absent in most countries. Knowledge of the full scope of tobacco harm in populations may form the basis for healthier behavior, de-normalization of smoking, and a consensus about necessary public policy. However, many populations may be poorly-informed about the risks, and this ignorance may undermine both effective policymaking and implementation of tobacco control policies. We present knowledge and risk perceptions about smoking tobacco smoke exposure in Israel.

Methods: A nationally-representative phone survey was conducted in Israel ( $n=505$; response rate $=61 \%$ ). We assessed knowledge about active and passive smoking using four questions, three of which addressed knowledge about harm, and one of which addressed knowledge of tobacco-related harm relative to knowledge of harm due to traffic accidents. The three questions which addressed knowledge of harm were combined into a composite score. We also asked four risk perception questions concerning tobacco smoke exposure, which were measured on a 7-point Likert scale and then combined. Multivariable logistic regression and linear models were used to identify whether smoking status or socio-demographic variables were associated with knowledge of harm, comparative knowledge of harm, and risk perceptions.

Results: Just two in five respondents, and one in five respondents who were current smokers, accurately answered three simple questions about harms of smoking. Fewer than three in ten respondents, and fewer than one in five smokers, knew that smoking causes more damage than traffic accidents. Many (30.3\%) were unaware that tobacco smoke exposure causes both lung cancer and heart disease, 27.7\% did not know that smoking both shortens life and injures quality of life, and $31.1 \%$ did not know that smoking-attributable health problems will afflict all or most heavy smokers. Overall, risk perceptions regarding tobacco smoke exposure were high (mean $=24.5$, SD:4.5, on a scale of 7-28, with 28 the indicating highest level). Smoking status was consistently associated with lower levels of knowledge, comparative knowledge, and risk perceptions, with current smokers having the lowest levels of knowledge and the lowest risk perceptions.
\end{abstract}

Conclusions: Like many others, Israelis, and particularly Israeli smokers, do not fully grasp tobacco's true dangers. Effective communication of the full range of tobacco risks to the public, with a focus on communication with smokers, is an essential component of comprehensive tobacco control policy.

Keywords: Tobacco, Smoking, Secondhand smoke, Risk perceptions, Knowledge

\footnotetext{
* Correspondence: Rosenl@post.tau.ac.il

'Department of Health Promotion, School of Public Health, Sackler Faculty of

Medicine, Tel Aviv University, POB 39040, 69978 Ramat Aviv, Israel

${ }^{2}$ Center for Global Tobacco Control, Department of Social and Behavioral

Sciences, Harvard T. H. Chan School of Public Health, 677 Huntington Ave,

Boston, MA 02115, USA

Full list of author information is available at the end of the article
}

(c) The Author(s). 2019 Open Access This article is distributed under the terms of the Creative Commons Attribution 4.0 International License (http://creativecommons.org/licenses/by/4.0/), which permits unrestricted use, distribution, and

reproduction in any medium, provided you give appropriate credit to the original author(s) and the source, provide a link to the Creative Commons license, and indicate if changes were made. The Creative Commons Public Domain Dedication waiver (http://creativecommons.org/publicdomain/zero/1.0/) applies to the data made available in this article, unless otherwise stated. 


\section{Introduction}

The tobacco epidemic continues with its devastating toll, despite decades of research and extensive knowledge about the consequences of tobacco use [1]. World-wide, effective governmental policies are regularly blocked by tobacco industry lobbying [2]. Partial or unenforced advertising bans permit the tobacco industry to continue to lure young smokers into life-long tobacco addiction. Millions of non-smokers are regularly exposed to tobacco smoke [3], putting them at inadvertent risk, due to incomplete or poorly-enforced laws, or exposure in private places. Permanent smoking cessation is an elusive goal for many smokers, even when aided by first-line pharmaceutical and counseling approaches [4].

Dissemination of information of risks regarding tobacco products has an important influence on population knowledge and related behavior. For example, anti-smoking media campaigns have played an important role in influencing the public around the world. The Tips from a Former Smoker campaign in the US, which cost the Federal government \$54 million in 2012 [5], was found to increase both knowledge and risk perception [6], and ultimately led to an estimated 1.6 million Americans attempting to quit smoking [7]. There was a similar effect on knowledge following a media campaign, accompanied by health warning labels, in Mexico [8]. The impressive level of knowledge among Canadians has been attributed to the high-budget anti-smoking educational program established by their government, which designated $\$ 480$ million for an anti-smoking campaign, of which $40 \%$ was dedicated to mass media campaigns [9].

In contrast to policies in these countries, there has never been public funding for ongoing education of the Israeli public about tobacco products: public education campaigns are rare, limited in scope, and generally not funded by the government. Of note is the work done by the Israel Cancer Association, which has funded various campaigns over the years. Smoking prevalence declined in Israel for decades [10], but that decline has ceased in the past decade [11], with rising smoking rates among young adults recently reported [12]. This may be related to low levels of knowledge of harms due to smoking, as well as failure to update and extend once-strong tobacco-control policies [13]. Cigarette packs include the same small, text-only messages written over a decade ago, and Israel has not yet mandated graphic warnings. The tobacco industry, conversely, invests tens of millions of dollars annually in advertising and promotion of its products [10]. The public may thus be misinformed about the full scope of risks; however, monitoring of knowledge of tobacco-related harm and risk perceptions associated with smoking is not conducted systematically.

Some years ago, we conducted a nationally-representative study of Israeli adults regarding tobacco-related behaviors, attitudes, and beliefs. We previously reported on public support for smoke-free areas [14, 15]. The current paper presents data on knowledge and risk perceptions regarding use of and exposure to combustible cigarettes (CCs) among Israeli adults, by smoking status, and identifies correlates associated with knowledge and risk perceptions.

\section{Methods}

Study design and sampling strategy

The details of the study design and sampling strategy have been reported previously $[14,15]$. In brief, a national phone survey of Israeli adults was conducted in Israel by the Cohen Survey Institute at the end of 2010. The survey was representative of adults aged 18 and above living in private residences with land telephone lines. Sampling was done in stages, according to statistical areas (randomly sampled within constructed layers), residences within statistical areas (simple random sampling), and individuals within residences (last-birthday method).

Questionnaires were translated by professionals in the Cohen Institute. Respondents chose whether to complete the survey in Hebrew, Arabic, or Russian.

The planned sample size of 500 was calculated to allow sufficient precision in estimating the study's primary endpoint: public support for smoke-free air, which was previously reported [14]. In order to obtain a $60 \%$ response rate with a final sample size of 500, 1077 phone numbers were selected for inclusion.

\section{Ethical approval}

The study was approved by the Tel Aviv University Ethics Committee in April, 2008.

\section{Questionnaire and variables}

All relevant questions can be found in Additional file 1.

\section{Socio-demographic variables}

Population sector was determined from questions about religion, birthplace, and language of interview. All those who identified as Jews were considered part of the Jewish sector. All who identified as Muslim or Druze were considered part of the Arab sector. Those who identified as Christians were categorized into population sector according to birthplace and language of interview. Those who did not specify a religion, but who answered in Arabic, were considered part of the Arab sector.

Age, sex, education, and family income level were asked using a standard set of questions used by the Cohen Institute. We categorized age into four categories: 18-29; 30-49; 50-65; over 65. Information was asked about highest educational institution at which the respondent studied. We collapsed the possible six options into three categories: < 12 years, 12 years, > 12 years. 
We asked about income level using two questions. The first referred to family economic status (How would you rate the financial status of your family?), and had five possible levels: very high, high, moderate, low, very low. The second asked about family income. It began with the statement, "The average family income in Israel today is about NIS 11,000" and asked whether family income was much above average, above average, equal, less than average, or much below average. Because we expected (and found) correlations between these two questions, we opted to include just one of the questions in our main analyses. The question on family financial status was chosen for the main analyses because: 1- financial status in Israel, as in many other countries, is not solely a function of monthly income; and, 2 - there were numerous missing values on the measure of family income. A sensitivity analysis was performed using the family income variable.

\section{Smoking status}

Smoking status referred to use of combustible cigarettes, and was originally asked using five categories (Regular smoker, Occasional smoker, Former regular smoker, Former occasional smoker, Never smoker). We recoded these to three categories (Current smoker, Former smoker, Never smoker).

\section{Knowledge and risk perceptions}

We used previous questions and questionnaires to inform our questions about knowledge and risk perceptions [16, 17], including some developed and validated by authors (LJR, DR, RS) of this paper [14, 18]. Most of the questions were originally written in English or taken from English publications and translated to Hebrew.

Four knowledge questions were asked. Three of them concerned harm due to smoking, and are referred to in this paper as "knowledge of harm". The first was about the effect of smoking on life expectancy, the second about whether the effect of ongoing exposure to passive smoke increases the risk of lung and heart disease, and the third was about whether smoking causes general health problems. We also asked one comparative harm question: whether the number of smoking-attributable deaths was greater, equal, or less than the number of deaths attributable to traffic accidents. This is referred to in this paper as "comparative harm".

The exact questions, and answers, are available in Additional file 1.

In order to examine risk perceptions regarding secondhand smoke, we used questions relating both to likelihood of harm and severity of harm, as per the Health Belief Model [19], and in continuation of our previous work on risk perception [18]. Four questions were asked on a 1-7 point Likert Scale. The first question asked the likelihood that a child exposed to smoking in a car will be harmed. The second question queried the likelihood that an adult exposed to secondhand smoking will be harmed. For these two questions, 1 represented low likelihood and 7 indicated high likelihood. The third question asked about the severity of the damage to a child travelling in a car with people smoking. The fourth question queried the severity of the damage to an adult exposed regularly to secondhand smoking. For these two questions, 1 represented minimal damage and 7 meant severe damage. Those who did not provide an answer due to refusal or because they did not know the answer were coded as "9", which was considered missing in all analyses.

\section{Composite scores}

The Composite Knowledge Score (CKS) combined responses to three questions covering basic knowledge of the effects of smoking. Respondents choosing the correct option received one point in their CKS for each correct answer. Incorrect answers garnered zero points in their CKS. Those answering, "Don't know" to a particular question were included and given a zero for that question. Those refusing to answer were excluded from the analysis. The maximum total score was three, and the minimum was zero.

In cases where the respondents had answered all three questions, we created a binary knowledge summary variable (CKS-BIN) based on answering the three questions assessing knowledge of harm correctly (Yes/No). Those respondents who answered all three questions correctly received a value of one and those who answered all the questions but didn't answer them all correctly received a value of zero. All other respondents received a value of "missing".

The Composite Risk Perception Score (CRPS) examined the participant's perception of risk, and was based on summing the four risk perception questions. Those who did not provide an answer to any of these four questions were excluded. The maximum total CRPS score was 28 , and the minimum was four. We calculated Cronbach's alpha for CRPS.

\section{Validation}

As previously reported, in addition to the initial validation done on the risk perception questions prior to the conduct of this survey [18], the entire questionnaire was validated in Hebrew. All questions were piloted on a separate sample of 15 individuals. Then, the questionnaire was validated using a test-retest approach, with an interval of one week, with 20 individuals. The final questionnaire was professionally translated from Hebrew to Arabic and Russian. 


\section{Statistical analyses}

We calculated percent of respondents who correctly answered each of the three knowledge questions, and the CKS-BIN, by smoking status and overall. We examined differences in CKS-BIN by population sector, gender, age category, and smoking status using the Chi-squared test. We used logistic regression to perform univariable analyses on educational level and family financial status, to account for the continuous nature of those variables. We used multivariable logistic regression to examine the influence of the same set of variables on CKS-BIN. We present the adjusted odds ratios (ORs) with confidence intervals (CIs) and $p$-values.

We present means, standard deviations, and n's of CRPS by smoking status and levels of possible explanatory variables for the risk perception questions. One-way analysis of variance was used to test for differences in CRPS by smoking status. We used multivariable analysis of variance to examine the influence of population sector, gender, age category, smoking status, educational level, and family financial status on CRPS. We present the Least Squared Means and $p$-values.

For all analyses, socio-economic status [SES] was based on reported family financial status. We also performed a sensitivity analysis using reported family income instead of family financial status in the multivariable models.

The analyses were conducted using the statistical programs R and SAS Version 9.4.

\section{Results}

\section{Study sample}

The total sample size was 505 . In order to achieve this with a response rate of at least $60 \%, 1077$ numbers were originally selected for inclusion. After excluding 168 numbers which were disconnected, 47 faxes or modems, and 33 businesses, 829 phone numbers were available. Full interviews were obtained from 505, giving a response rate of $61 \%$. Among non-respondents, $23 \%$ were refusals, $10 \%$ didn't answer, $5 \%$ were excluded due to communication problems (individuals didn't speak Hebrew, Russian, or Arabic, or had difficulties in hearing or understanding), and $1 \%$ were partial interviews.

There were 420 respondents categorized to the Jewish sector (417 Jews, one Christian, and 2 USSR-born respondents who did not specify a religion) and 84 respondents to the Arab sector (61 Muslims, 8 Druze, 12 Israeli-born Christians, one Lebanese-born Christian, and two Israeli-born respondents who did not specify a religion and who answered in Arabic). Population sector could not be determined for 1 participant.

Of the 505 respondents, about half were male and half female (females: 50.7\%, males: 49.3\%). About half $(52.3 \%)$ had at least some post-high school education. Most (62.3\%) reported their family's financial status as average, while $21.7 \%$ reported above-average income and $16.0 \%$ reported below-average income. Current smokers comprised $22.3 \%$ of the sample, $26.9 \%$ were former smokers, and $50.8 \%$ were never smokers.

Distributions of nationality (Jews/Non-Jews), educational level, and gender were similar to those reported by the Central Bureau of Statistics [14]. The percentage of current smokers was very close to that reported in the 2010 Health Ministry report (23.3\%) [20].

Distributions of all variables by smoking status are presented in Table 1.

\section{Descriptive findings}

Results about knowledge of harm (combined and individually), comparative harm, and risk perceptions are presented in Table 2 by smoking status. Of all respondents, $41.9 \%$ answered the three basic questions correctly, with only $21.6 \%$ of current smokers answering the three questions correctly. About $70 \%$ of respondents correctly answered each of three questions: that smoking shortens life and damages quality of life; that exposure to smoke from combustible cigarettes harms both heart and lungs; and that all or most heavy smokers suffer health problems due to their smoking. The question about the burden of mortality from smoking relative to traffic accidents led to the least-accurate answers: over $70 \%$ did not correctly answer this question. The same question also led to the highest percent (36.3\%) of declarations of "don't know" of any question. Current smokers' responses were consistently the least accurate.

Across all respondents, the question with the highest associated risk perception was about the likelihood of affecting the health of the child who is present in a car in which smoking takes place (Mean:6.36; SD: 1.16, $n=$ 487), and the question with the lowest associated risk perception concerned the severity of damage to adults' health from smoking which occurs around them (Mean: 5.87; SD: $1.47 ; N=470)$. The other two questions fell in the middle (Likelihood of an adult being harmed by tobacco smoke exposure: Mean 6.15; SD: 1.29; $N=486$; Severity of harm to child exposed in a car: Mean: 6.09; SD: $1.41 ; N=473)$. Overall, respondents perceived risk at a value of $24.5(\mathrm{SD}=4.5)$ out of 28 possible points. Cronbach's alpha for CRPS was 0.89 , indicating that the items in the test are highly correlated.

\section{Univariable analyses}

Univariable analyses of knowledge of harm, comparative knowledge, and risk perceptions are presented by population sector, gender, age category, smoking status, educational level, and family financial status in Table 3. Smoking status was significantly associated with knowledge of harm $(p<.001)$, while the association with 
Table 1 Smoking status (Current, Former, Never) of study participants, by levels of demographic variables

\begin{tabular}{|c|c|c|c|c|c|c|}
\hline & & $\begin{array}{l}\text { Current Smoker } \\
\%(N=112)\end{array}$ & $\begin{array}{l}\text { Former Smoker } \\
\%(N=135)\end{array}$ & $\begin{array}{l}\text { Never Smoker } \\
\%(N=255)\end{array}$ & $\begin{array}{l}\text { Overall \% } \\
(N=502)\end{array}$ & $P$-value \\
\hline Overall $(N=502)$ & & 22.3 & 26.9 & 50.8 & & \\
\hline \multirow[t]{2}{*}{ Population Sector $(N=501)$} & Jewish $(N=417)$ & 21.8 & 28.5 & 49.6 & 83.2 & 0.202 \\
\hline & $\operatorname{Arab}(N=84)$ & 25.0 & 19.0 & 56.0 & 16.8 & \\
\hline \multirow[t]{2}{*}{ Gender $(N=502)$} & Male $(N=248)$ & 29.4 & 34.3 & 36.3 & 49.4 & $<0.001$ \\
\hline & Female $(N=254)$ & 15.4 & 19.7 & 65.0 & 50.6 & \\
\hline \multirow[t]{4}{*}{ Age group $(N=496)$} & $18-29(N=88)$ & 17.1 & 22.7 & 60.2 & 17.7 & $<0.001$ \\
\hline & $30-49(N=185)$ & 31.4 & 16.2 & 52.4 & 37.3 & \\
\hline & $50-65(N=148)$ & 19.6 & 37.2 & 43.2 & 29.8 & \\
\hline & $>65(N=75)$ & 12.0 & 38.7 & 49.3 & 15.1 & \\
\hline \multirow[t]{3}{*}{ Educational level $(N=498)$} & $<12(N=48)$ & 29.2 & 39.6 & 31.3 & 9.6 & 0.002 \\
\hline & $12 N=189)$ & 28.0 & 21.7 & 50.3 & 38.0 & \\
\hline & $>12(N=261)$ & 16.5 & 28.7 & 54.8 & 52.4 & \\
\hline \multirow[t]{5}{*}{ Family financial status $(N=487)$} & Very low $(N=19)$ & 21.1 & 26.3 & 52.6 & 3.9 & 0.888 \\
\hline & Low $(N=59)$ & 23.7 & 32.2 & 44.1 & 12.1 & \\
\hline & Moderate $(N=303)$ & 23.1 & 26.4 & 50.5 & 62.2 & \\
\hline & $\operatorname{High}(N=86)$ & 18.6 & 27.9 & 53.5 & 17.7 & \\
\hline & Very high $(N=20)$ & 30.0 & 15.0 & 55.0 & 4.1 & \\
\hline
\end{tabular}

comparative harm approached statistical significance $(p=.059)$. Just $21.6 \%$ of current smokers, but $50.0 \%$ of never-smokers, accurately answered all three questions about harm correctly. The percentage with correct answers among those with post-high school education was double the percentage among those who had not even attended high school (>12 years: $49.8 \%$ correct; $<12$ years: $25 \%$ correct, $p<.001)$. Younger age groups were associated with higher levels of knowledge of harm. Male gender was associated with greater comparative knowledge (Males: $34.2 \%$, Females: $23.1 \%, p=.007$ ).

Risk perception was significantly $(p<0.001)$ associated with smoking status. Current smokers had the lowest risk perceptions (Mean: 22.7, SD: 6.0), and never smokers the highest risk perceptions (Mean: 25.1, SD: 3.9). Those in the Arab sector reported higher perceptions of risk than those in the Jewish sector (Arab: Mean: 26.1, SD: 3.3; Jewish: Mean: 24.2, SD: 4.7, $p$ $<.001)$. Risk perceptions was associated with age group of the respondent $(p=0.017)$, with older respondents holding higher levels of risk perceptions.

\section{Multivariable models}

Results of the multivariable statistical models are presented in Table 4.

\section{Knowledge of harm}

Multivariable results were similar to findings from the univariable analyses: smoking status was significantly associated with knowledge of harm, with current smokers having the lowest levels and never smokers the highest levels $(p<.001)$. Those in the younger age groups were better informed than those in the older age groups $(p=.015)$, and those with higher educational levels were better informed $(p=.025)$.

\section{Knowledge of comparative harm}

Multivariable results were similar to findings from univariable analyses. In both cases, current smokers were less informed, with a statistically significant result in the multivariable analyses $(p=.017)$. Males were better informed relative to females $(p=.002)$ in the multivariable as in the univariable analysis. Population sector, age group, educational sector, and family financial status were not significant, as in the univariable models.

\section{Risk perceptions}

Again, findings from the multivariable model closely followed those from the univariable models. Population sector was statistically significant, with Arabs holding higher risk perceptions than Jews $(p<.001)$. Older individuals held higher risk perceptions $(p=.001)$. Never smokers had the highest risk perceptions and current smokers the lowest $(p<.001)$. Neither gender, educational level, nor family financial status were associated with perception levels. 
Table 2 Knowledge about tobacco harm and exposure among Israelis, for individual questions, by smoking status

\begin{tabular}{|c|c|c|c|c|c|c|c|}
\hline & & $\begin{array}{l}\text { Current } \\
\text { Smoker (\%) }\end{array}$ & $\begin{array}{l}\text { Former } \\
\text { Smoker (\%) }\end{array}$ & $\begin{array}{l}\text { Never } \\
\text { Smoker (\%) }\end{array}$ & Overall (\%) & $\mathrm{N}$ & $p$-value \\
\hline \multirow[t]{6}{*}{ Knowledge 1: Length and quality of life } & Shortens life & 5.4 & 9.0 & 7.9 & 7.6 & 38 & \\
\hline & Damages quality of life & 17.1 & 9.7 & 9.1 & 11.0 & 55 & \\
\hline & $\begin{array}{l}\text { Shortens life and } \\
\text { damages quality }\end{array}$ & 57.7 & 75.4 & 77.1 & 72.3 & 360 & \\
\hline & Neither & 7.2 & 0 & 0.8 & 2.0 & 10 & \\
\hline & Don't know & 12.6 & 6.0 & 5.1 & 7.0 & 35 & \\
\hline & N & 111 & 134 & 253 & & 498 & $<.001$ \\
\hline \multirow{6}{*}{$\begin{array}{l}\text { Knowledge 2: Secondhand smoke causes lung cancer } \\
\text { and/or heart disease }\end{array}$} & Lung cancer & 5.4 & 9.0 & 12.8 & 10.1 & 50 & \\
\hline & Heart disease & 0.9 & 0.8 & 2.0 & 1.4 & 7 & \\
\hline & Both & 57.7 & 73.1 & 73.2 & 69.7 & 345 & \\
\hline & Neither & 9.0 & 5.2 & 2.0 & 4.4 & 22 & \\
\hline & Don't know & 27.0 & 11.9 & 10.0 & 14.3 & 71 & \\
\hline & N & 111 & 134 & 250 & & 495 & $<.001$ \\
\hline \multirow{5}{*}{$\begin{array}{l}\text { Knowledge 3: Smoking in Israel kills less than/more } \\
\text { than/same as are killed in traffic accidents }\end{array}$} & Less & 36.9 & 17.0 & 21.6 & 23.8 & 118 & \\
\hline & More & 19.8 & 29.6 & 32.0 & 28.6 & 142 & \\
\hline & Same & 9.9 & 11.1 & 12.0 & 11.3 & 56 & \\
\hline & Don't know & 33.3 & 42.2 & 34.4 & 36.3 & 180 & \\
\hline & $N$ & 111 & 135 & 250 & & 496 & .008 \\
\hline \multirow{7}{*}{$\begin{array}{l}\text { Knowledge 4: How many heavy smokers suffer or will } \\
\text { suffer from health problems because of their smoking? }\end{array}$} & Everyone & 8.0 & 17.8 & 19.6 & 16.5 & 83 & \\
\hline & Most & 47.3 & 51.9 & 54.9 & 52.4 & 263 & \\
\hline & Half & 23.2 & 14.8 & 14.1 & 16.3 & 82 & \\
\hline & Minority & 10.7 & 2.2 & 2.8 & 4.4 & 22 & \\
\hline & No one & 1.8 & 0 & 0.8 & 0.8 & 4 & \\
\hline & Don't know & 8.9 & 13.3 & 7.8 & 9.6 & 48 & \\
\hline & N & 112 & 135 & 255 & & 502 & $<.001$ \\
\hline \multirow[t]{3}{*}{$\begin{array}{l}\text { Knowledge of harm (based on } 3 \text { questions [Knowledge } \\
\text { 1, Knowledge 2, Knowledge 4]) }\end{array}$} & $\begin{array}{l}3 \text { questions not answered } \\
\text { correctly }\end{array}$ & 78.4 & 56.4 & 50.0 & 58.1 & 287 & \\
\hline & $\begin{array}{l}3 \text { questions answered } \\
\text { correctly }\end{array}$ & 21.6 & 43.6 & 50.0 & 41.9 & 207 & \\
\hline & $N$ & 111 & 133 & 250 & & 494 & $<.001$ \\
\hline
\end{tabular}

\section{Sensitivity analysis}

For knowledge of harm, the multivariable analysis which included family income produced estimates which were in the same direction as the analysis using family financial status for all variables. (Note: The direction of the effect of family income and family financial status seemed to differ, but did not. Family financial status used descending order, while family income used ascending order.) When including family financial status in the model, educational level approached significance $(p=.054)$, and higher family income was significantly associated with more accurate responses $(p=.008)$. No differences in statistical significance $(<.05$ or $>.05)$ were found for comparative knowledge or for risk perceptions between the multivariable models using family income and the models using family financial status as a proxy for socio-economic status.

\section{Discussion}

The central findings of this study are that, 1) as a group, Israeli adults are only partially informed about the harms of tobacco smoking and exposure, and 2) smokers are particularly ignorant. Just over two in five respondents correctly answered three basic questions about knowledge of harm; among smokers, just over one in five respondents answered these three questions correctly. About 30\% of respondents answered each of three of the knowledge questions incorrectly. Of particular interest was the comparative harm question which addressed numbers of deaths caused by smoking versus number of deaths caused by tobacco relative to traffic accidents. 
Table 3 Univariable analyses of knowledge and risk perceptions

\begin{tabular}{|c|c|c|c|c|c|c|c|}
\hline & & $\begin{array}{l}\text { Knowledge of harm, } \\
3 \text { questions combined, } \\
\% \text { correct }(N=495)\end{array}$ & $\begin{array}{l}p \text {-value (Chi-squared } \\
\text { except where } \\
\text { indicated otherwise) }\end{array}$ & $\begin{array}{l}\text { Knowledge of } \\
\text { comparative harm, } \\
\text { relative to traffic } \\
\text { accidents, \% correct } \\
(\mathrm{N}=497)\end{array}$ & $\begin{array}{l}p \text {-value (Chi- } \\
\text { squared except } \\
\text { where indicated } \\
\text { otherwise) }\end{array}$ & $\begin{array}{l}\text { Perception } \\
\text { Scale Mean } \\
\text { (SD) }(N=465)\end{array}$ & $p$-value, N \\
\hline \multirow[t]{2}{*}{ Population Sector } & Arab & $38.6(83)$ & 0.483 & $27.4(84)$ & 0.791 & $26.1(3.3) 84$ & $<.001464$ \\
\hline & Jewish & $42.7(412)$ & & $28.8(413)$ & & 24.2 (4.7) 380 & \\
\hline \multirow[t]{2}{*}{ Gender } & Male & $38.5(244)$ & 0.120 & $34.2(246)$ & 0.007 & 24.4 (4.8) 221 & 0.455465 \\
\hline & Female & $45.4(251)$ & & $23.1(251)$ & & 24.7 (4.3) 244 & \\
\hline \multirow[t]{4}{*}{ Age group } & $18-29$ & $52.3(88)$ & 0.014 & $33.0(88)$ & 0.416 & $23.4(4.8) 83$ & 0.017459 \\
\hline & $30-49$ & $45.6(182)$ & & $25.1(183)$ & & $24.3(4.7) 173$ & \\
\hline & $50-65$ & 39.7 (146) & & $31.8(148)$ & & $25.2(4.2) 136$ & \\
\hline & $>65$ & $28.4(74)$ & & $26.0(73)$ & & $25.2(3.8) 67$ & \\
\hline \multirow[t]{3}{*}{ Educational level } & $<12$ & $25.0(48)$ & $<0.001^{\mathrm{a}}$ & $25.0(48)$ & $0.539^{\mathrm{a}}$ & $24.7(5.5) 45$ & 0.551462 \\
\hline & 12 & $35.8(190)$ & & $28.6(189)$ & & 24.6 (4.5) 178 & \\
\hline & $>12$ & $49.8(253)$ & & $29.7(256)$ & & $24.4(4.5) 239$ & \\
\hline \multirow[t]{5}{*}{ Family financial status } & Very low & $27.8(18$ & $0.090^{\mathrm{a}}$ & $27.8(18)$ & $0.127^{a}$ & $23.9(4.2) 18$ & 0.930450 \\
\hline & Low & $28.8(59)$ & & $18.6(59)$ & & $24.7(4.7) 53$ & \\
\hline & Moderate & $44.0(300)$ & & $29.3(300)$ & & 24.5 (4.6) 281 & \\
\hline & High & $48.8(84)$ & & $37.2(86)$ & & $24.6(3.8) 80$ & \\
\hline & Very high & $40.0(20)$ & & $25.0(20)$ & & $23.9(7.2) 18$ & \\
\hline \multirow[t]{3}{*}{ Smoking Status } & Current & $21.6(111)$ & $<0.001$ & $19.8(111)$ & 0.059 & $22.7(6.0) 101$ & $<.001464$ \\
\hline & Former & $43.6(133)$ & & $29.6(135)$ & & 24.9 (4.0) 119 & \\
\hline & Never & $50.0(250)$ & & $32.0(250)$ & & $25.1(3.9) 244$ & \\
\hline
\end{tabular}

${ }^{a}$ Logistic regression with continuous explanatory variable.

Over $70 \%$ of Israelis, and $80 \%$ of current smokers, were unaware that smoking causes more deaths than traffic accidents. Just over one-third of respondents incorrectly answered "less" or "same", while over one-third (36.3\%) answered, "I don't know." This occurred despite the fact that Israeli deaths due to smoking (approximately 8000) [21] are over twenty times greater than those due to traffic accidents (352) [22]. Risk perceptions were high overall, with an average of 24.5 (SD 4.5) out of a possible 28.

About $80 \%$ of Israelis knew that secondhand smoke exposure causes lung cancer, and about $70 \%$ knew that secondhand smoke exposure causes heart disease. Among smokers, these numbers were $63 \%$ and 59\%, respectively. While this denotes ignorance among many respondents (particularly among smokers), international figures show that knowledge varies widely by country (Table 5) [9, 23-26], and is not universally high elsewhere, either. The causal effect of secondhand smoke on lung cancer in Canada, the UK, Australia, and the U.S. was understood by 79.6, 75.2, 69.0, and $68.1 \%$ of respondents, respectively, according to a 2006 report [27]. In a 2014 report about Bangladesh, $60 \%$ of respondents unexposed to tobacco smoke, and $40 \%$ of exposed respondents, were aware of this relationship [28]. Knowledge was reportedly lower in a pilot study in India published in $2012(30-45 \%)$ [29], though not in China (nearly $60 \%$ ), according to a 2010 report [26]. Knowledge that secondhand smoke causes cardiovascular disease in nonsmokers in India was poor, ranging from about 5\% to under 40\% [29].

Consistent with previous reports, we found that knowledge and risk perceptions were lower among current smokers than among others. Previous research has shown that nonsmokers and former smokers viewed smoking as a riskier behavior than did current smokers [30]. Nonsmokers also viewed exposure to secondhand smoking as more risky, relative to smokers [18].

Previous research has repeatedly shown that other factors, in addition to smoking status, are associated with knowledge and risk perceptions. Within countries, educational level and socio-economic status are of particular importance. In studies conducted in the US, UK, Canada, Australia [9, 31], Bangladesh [32], and Vietnam [33], educational level has emerged as one of the strongest predictors of smoking knowledge. Knowledge and risk perceptions also increase with socioeconomic status (SES); this has been observed in the US, UK, Canada, Australia [9], and Morocco [24]. The International Tobacco Control study found that in the United States, Canada, United Kingdom, and Australia [9], the vast 
Table 4 Multivariable statistical model results

\begin{tabular}{|c|c|c|c|c|c|c|}
\hline \multirow[t]{2}{*}{ Variable } & $\begin{array}{l}\text { Knowledge of } 3 \text { questions } \\
(\mathrm{Y} / \mathrm{N})(\mathrm{N} \text { in model }=471)\end{array}$ & $p$-value & $\begin{array}{l}\text { Knowledge of comparative } \\
\text { harm relative to traffic } \\
\text { accidents ( } \mathrm{N} \text { in model }=473 \text { ) }\end{array}$ & $p$-value & $\begin{array}{l}\text { Risk perceptions of harm } \\
\text { due to involuntary exposure } \\
\text { to tobacco smoke ( } \mathrm{N} \text { in } \\
\text { model }=441 \text { ) }\end{array}$ & \multirow[t]{2}{*}{$p$-value } \\
\hline & Odds Ratio (Confidence Interval) & & Odds Ratio (Confidence Interval) & & Least Square Means & \\
\hline Population Sector & & 0.188 & & 0.668 & Jewish: 23.7 & $<0.001$ \\
\hline Arab vs. Jewish & $0.70(0.41,1.19)$ & & $0.89(0.51,1.54)$ & & Arab: 26.1 & \\
\hline Gender & & 0.525 & & 0.002 & Male: 25.0 & 0.476 \\
\hline Female vs. Male & $1.14(0.76,1.71)$ & & $0.50(0.33,0.77)$ & & Female: 24.7 & \\
\hline Age group & & 0.015 & & 0.539 & $65+: 25.6$ & 0.001 \\
\hline $18-29$ vs. $65+$ & $3.01(1.47,6.19)$ & & $1.25(0.60,2.61)$ & & 18-29: 23.4 & \\
\hline $30-49$ vs. $65+$ & $2.50(1.29,4.85)$ & & $1.00(0.50,1.99)$ & & 30-49: 24.8 & \\
\hline $50-65$ vs. $65+$ & $1.78(0.93,3.43)$ & & $1.41(0.73,2.75)$ & & 50-65: 25.8 & \\
\hline Educational level & $1.43(1.05,1.96)$ & 0.025 & $1.11(0.80,1.53)$ & 0.538 & $N R$ & 0.309 \\
\hline Family financial status & $0.83(0.64,1.07)$ & 0.149 & $0.88(0.67,1.15)$ & 0.347 & NR & 0.756 \\
\hline Smoking Status & & $<0.001$ & & 0.017 & Never: 25.8 & $<0.001$ \\
\hline Current vs. Never & $0.28(0.16,0.49)$ & & $0.44(0.25,0.78)$ & & Current: 23.3 & \\
\hline Former vs. Never & $0.93(0.58,1.48)$ & & $0.70(0.43,1.15)$ & & Former: 25.5 & \\
\hline
\end{tabular}

NR Not Relevant.

majority of respondents across SES strata and educational levels in these countries were able to answer some questions correctly. For example, the least-informed populations were poorly-educated Americans, of whom 83.7\% knew smoking causes heart disease, and low-income British, of whom $90.5 \%$ knew that smoking causes lung cancer. Canadian respondents scored the highest, with the adjusted odds ratio (95\%) from logistic regression being $1.61(1.33-1.95)$ regarding heart disease, and $1.16(0.89-1.52)$ regarding lung cancer [relative to the US population].

Other than for smoking status, we did not observe consistent patterns among the socio-demographic and economic variables on our three endpoints of harm, comparative harm, and risk perceptions. There were no differences between population sectors in knowledge of harm or comparative harm, though risk perceptions were slightly but significantly higher among Arabs than among Jews. Gender differences were apparent only for the knowledge of comparative harm endpoint; men were better informed than women about the deaths caused by tobacco relative to the deaths caused by traffic accidents. Respondents in younger age categories were better informed about harm relative to older respondents, but older respondents had higher risk perceptions. Those with higher education were better informed about harm, but not about comparative harm, than those with lower educational levels, and did not differ on risk perceptions. Family financial status was not significantly associated with knowledge of harm, knowledge of comparative harm, or risk perceptions. In the sensitivity analysis, we observed that family income was not associated with comparative knowledge or risk perceptions, but those with higher incomes did have higher levels of knowledge.

A recent report suggested that smoking rates in Israel have increased in recent years among young adults (2009: Past year: 37.6\% Past month: 33.0\%; 2016: Past year: $45.7 \%$, Past month: 35.2\%) [12]. This worrisome finding, along with the failure substantially to lower adult smoking prevalence - during a time of large reductions elsewhere, in countries such as the U.S. [34], Canada [35], and the UK [36] -- is a clear call to immediate action for tobacco control. Taxation is the strongest tobacco control tool readily available to policy-makers today. At present in Israel, taxation on roll-your-own (RYO) cigarettes is substantially less than that on packaged cigarettes, making RYO cigarettes particularly appealing to youth and socially disadvantaged individuals, and possibly discouraging quitting among smokers [37]. Raising taxes on RYO cigarettes is an important move which should be taken immediately; the issue is currently being discussed in the Supreme Court. Increasing the age at which tobacco can be legally sold from 18 to 21 is likewise a step of tremendous importance, particularly since roughly half of Israeli smokers began smoking between the ages of 18-21 [38]. That step would also assist the army in its battle for tobacco control. A complete advertising ban on all tobacco products, as required by Israel's ratified agreement with the World Health Organization's Framework Convention for Tobacco Control (FCTC), and also as stipulated in the 
Table 5 Knowledge about tobacco-attributable heart and lung disease risk in different countries

\begin{tabular}{|c|c|c|c|}
\hline \multirow[t]{2}{*}{ Study } & \multirow[t]{2}{*}{ Country } & \multicolumn{2}{|c|}{ Respondents who believe that smoking causes } \\
\hline & & Lung cancer (\%) & Heart Disease $^{\mathrm{a}}$ or Heart Attack ${ }^{\mathrm{b}}(\%)$ \\
\hline \multirow[t]{4}{*}{ Siahpush, 2006} & USA & 94.4 & $85.8^{\mathrm{a}}$ \\
\hline & Canada & 94.8 & $90.9^{\mathrm{a}}$ \\
\hline & UK & 93.7 & $89.6^{\mathrm{a}}$ \\
\hline & Australia & 94.3 & $88.6^{\mathrm{a}}$ \\
\hline Yang, 2010 & China & 73 & $40.2^{\mathrm{a}}$ \\
\hline Fakir, 2011 & Morocco & 63 & $22^{a}$ \\
\hline \multirow[t]{4}{*}{ Agaku, 2014} & 29 African countries* & Median:5.1 & Median:12.8 \\
\hline & Tunisia & Lower limit: 0 & Lower limit: $0^{\mathrm{a}}$ \\
\hline & Somaliland, Somalia & Upper limit: 80.4 & \\
\hline & Malawi & & Upper limit: $36.6^{\mathrm{a}}$ \\
\hline Minh An, 2013 & Vietnam & 95.8 & $60.9^{\mathrm{b}}$ \\
\hline \multirow[t]{14}{*}{ Gupta, 2014} & Thailand & 97.4 & $75.2^{\mathrm{b}}$ \\
\hline & Uruguay & 96.9 & $92.3^{\mathrm{b}}$ \\
\hline & Turkey & 96.8 & $94.4^{\mathrm{b}}$ \\
\hline & Mexico & 96.6 & $80.5^{\mathrm{b}}$ \\
\hline & Egypt & 96 & $94.8^{\mathrm{b}}$ \\
\hline & Brazil & 96 & $87.1^{b}$ \\
\hline & Vietnam & 95.2 & $63^{b}$ \\
\hline & Bangladesh & 94.2 & $90.2^{\mathrm{b}}$ \\
\hline & Poland & 91.8 & $79.5^{\mathrm{b}}$ \\
\hline & Philippines & 91.5 & $77.6^{\mathrm{b}}$ \\
\hline & Ukraine & 89.7 & $75.5^{\mathrm{b}}$ \\
\hline & Russian Federation & 88.5 & $65.7^{b}$ \\
\hline & India & 87.2 & $65.1^{b}$ \\
\hline & China & 79 & $40.6^{b}$ \\
\hline
\end{tabular}

${ }^{*}$ Reported median and range.

governmentally-approved National Plan for Reduction in Smoking and its Damage, should be passed immediately, without any exemptions. Display bans, plain packaging, and graphic warnings are other important measures which have been enacted in many other countries and should be legislated in Israel. If passed, the legislation currently under discussion in the Economics Committee of the Knesset will contribute to bringing Israel back into the company of other progressive nations on tobacco control, though that bill is weakened by the exemption for advertising in the print press and the lack of required graphic warnings. In order to stay ahead of industry promotional efforts and decrease smoking prevalence, core funding for tobacco control is essential. Such a program should include funding for media campaigns such as the Truth Campaign [39] which has been so successful in the U.S., and strict enforcement of all tobacco control laws, including those related to youth access, advertising, and laws against smoking in public places. Laws to protect non-smokers from tobacco exposure, and Israel's strong smoking cessation program, which is available to all through Israel's comprehensive national health insurance system, should be strengthened. Systematic monitoring of behavior, knowledge, and attitudes of Israelis towards all nicotine and tobacco products, of tobacco and nicotine industry activity in Israel, and of the impact of tobacco industry activity and governmental policy on population level smoking prevalence, is crucial.

Because higher risk perceptions among smokers are associated with greater likelihood of making quit attempts and, to some extent, sustained smoking abstinence [40], the findings from this paper suggest that policies promoting public education may be of great importance. Public information campaigns could be conducted through traditional media channels (television and radio) as well as digital media and social media (for example, Facebook). Because smokers have the lowest levels of knowledge and risk perceptions, targeting smokers is particularly important. Graphic warnings on 
cigarette packs, as are used in over one hundred countries, have shown greater effectiveness in communicating risk, as have larger warnings and those with more content, than have smaller, non-graphic warnings [27]. Recent advances in product packaging, including package inserts and on-cigarette messaging (for example, "smoking kills" printed on cigarettes), are also promising and should be considered [27, 41, 42]. All of the product packaging and display approaches are directed at smokers and potential smokers, and so should be particularly efficient. In Israel, stronger package warnings, including graphic package warnings, inserts, and on-cigarette warnings, could regularly expose 1.3 million current smokers to these critical messages, in a very cost-efficient manner.

Understanding public knowledge and risk perceptions about combusted tobacco is especially important given the rapidly-changing tobacco landscape. New tobacco and nicotine products, including but not limited to electronic cigarettes and heated tobacco products, are emerging globally and in Israel. There are deep divisions within the professional community about the short and long-term effects of these new products on individuals and populations [43]. Industry sources claim substantial harm reduction from specific emerging nicotine and tobacco products, and employ such claims when promoting these new products to policy makers and the public [44]. To date, the government has not provided Israelis with clear information on these issues. To formulate realistic, effective policy, it is essential to understand public knowledge and risk perceptions regarding the dangers of the combustible cigarette, and use that information to give high priority to educating the public about all tobacco and nicotine products so that individuals can make wise choices.

\section{Strengths and limitations}

The main strength of this study is that it was a nationally-representative study conducted in a broad, heterogeneous population, with a reasonably high response rate (61\%). This allows generalization of the findings to be made to the Israeli population on an important topic - knowledge and risk perceptions of Israelis concerning smoking --which has not previously been studied in this population. That the study was conducted some time ago (December, 2010) means that it provides good baseline information about knowledge and risk perceptions about smoking, prior to the recent introduction of emerging tobacco and nicotine products, such as IQOS and JUUL $[44,45]$. This is particularly important because, unlike in many other countries, such information is not available at all in the Israeli setting.

There are some methodological limitations. This was a landline-only survey. Because of the proliferation of cellphones in Israel, it is possible that some groups, particularly young people who owned cellphones but not landlines at the time of study, or people who owned landlines but did not use them frequently, are poorly-represented. Young adults who served in compulsory military service and lived in military housing (as opposed to returning home in the evenings) are likely under-represented. While the response rate was reasonable, we were unable to ascertain opinions of non-respondents.

The lack of standardized questions about knowledge and risk perceptions [46] limited our ability to make comparisons on all items. Question format may have affected participants' answers [47], and differences in methods pose a statistical challenge for comparison between studies. It is imperative to create a standard set of questions and answers to measure and compare a population's knowledge of the health effects of smoking.

Because this was not a very large dataset, we choose to focus our analyses on variables of greatest interest. Other variables, both measured and unmeasured, may have acted as confounders.

As is done in the great majority of population studies both in Israel and internationally about smoking, smoker status was based on self-report. Self-report has been validated as a measure of smoking status [48]. In this study, we obtained the information through telephone interviews. Self-report in the context of telephone interviews have been shown to under-estimate smoking status by $3-4 \%$ [49]. Therefore, it is reasonable to assume that a small percentage of smokers may not have identified as smokers, resulting in misclassification bias of a small percentage of respondents.

\section{Conclusions}

Like many others, Israelis do not fully grasp tobacco's true dangers. Effective communication of the full range of tobacco risks to the public, with targeting of smokers, is an essential component of comprehensive tobacco control policy.

\section{Additional file}

Additional file 1: Annotated Questionnaire. Sensitivity analysis: Multivariable statistical model results, using family income instead of family financial status. (DOCX 43 kb)

\section{Acknowledgements}

The authors thank Shira Kislev for helpful comments.

\section{Funding}

This study was supported by a grant from the Israel National Institute for Health Policy Research.

Availability of data and materials

We did not request permission from participants to make anonymous data available to the research community. Therefore, the raw data are not available for publication online. 


\section{Authors' contributions}

This research was initiated by LR and RS. LJR, RS, and DR obtained funding LR also oversaw the research, directed the statistical analysis and analyzed data, and drafted much of the original version of the paper. RS assisted with conceptualizing the issues and edited versions of the manuscript. DR contributed to the analysis plan, assisted with analytic issues, wrote parts of the manuscript, and carefully edited the entire manuscript. MT assisted with the statistical analysis. LZ assisted with the statistical analysis and drafted parts of the manuscript. All authors approved the final version of the manuscript.

\section{Ethics approval and consent to participate}

Ethical approval was obtained from the Tel Aviv University Ethics Committee. Participants were asked for their consent at the start of the telephone interviews.

\section{Consent for publication}

Participants were informed that the data would be used anonymously, for research purposes. All authors agreed to publication.

\section{Competing interests}

All authors declare that they have no competing interests.

\section{Publisher's Note}

Springer Nature remains neutral with regard to jurisdictional claims in published maps and institutional affiliations.

\section{Author details}

'Department of Health Promotion, School of Public Health, Sackler Faculty of Medicine, Tel Aviv University, POB 39040, 69978 Ramat Aviv, Israel. ${ }^{2}$ Center for Global Tobacco Control, Department of Social and Behavioral Sciences, Harvard T. H. Chan School of Public Health, 677 Huntington Ave, Boston, MA 02115, USA. ${ }^{3}$ Department of Sociology and Anthropology, Bar llan University, 5290002 Ramat-Gan, Israel. ${ }^{4}$ University of Toronto, Toronto M5S 1A1, Canada. ${ }^{5}$ Department of Statistics, Tel Aviv University, 69978 Ramat Aviv, Israel.

${ }^{6}$ Sackler Medical School, Tel Aviv University, 69978 Ramat Aviv, Israel.

Received: 10 June 2018 Accepted: 18 December 2018 Published online: 14 January 2019

\section{References}

1. Drope E, Schluger N. The Tobacco Atlas - 6th Edition. 2018. https:// tobaccoatlas.org/wp-content/uploads/2018/03/TobaccoAtlas_6thEdition_ LoRes_Rev0318.pdf.

2. Malone RE, Bialous SA. WHO FCTC article 5.3: promise but little progress: BMJ Publishing Group Ltd. Tobacco Control. 2014;23:279-80.

3. Oberg M, Jaakkola MS, Woodward A, Peruga A, Pruss-Ustun A. Worldwide burden of disease from exposure to second-hand smoke: a retrospective analysis of data from 192 countries. Lancet. 2011;377(9760):139-46.

4. Rosen L, Galili T, Kott J, Goodman M, Freedman LS. Diminishing benefit of smoking cessation medications during the first year: a meta-analysis of randomized controlled trials. Addiction. 2018;113:805-16. https:// onlinelibrary.wiley.com/doi/full/10.1111/add.14134.

5. Kornfield R, Smith KC, Szczypka G, Vera L, Emery S. Earned media and public engagement with CDC's "tips from former smokers" campaign: An analysis of online news and blog coverage. J Med Internet Res. 2015;17(1):e12. https://doi.org/10.2196/jmir.3645.

6. Duke JC, Davis KC, Alexander RL, MacMonegle AJ, Fraze JL, Rodes RM, et al. Impact of a US antismoking national media campaign on beliefs, cognitions and quit intentions. Health Educ Res. 2015;30(3):466-83.

7. CDC NewsRoom: More than 100,000 Americans quit smoking due to national media campaign. 2013. https://www.cdc.gov/media/releases/2013/ p0909-tips-campaign-results.html.

8. Thrasher JF, Murukutla N, Pérez-Hernández R, Alday J, Arillo-Santillán E, Cedillo C, et al. Linking mass media campaigns to pictorial warning labels on cigarette packages: a cross-sectional study to evaluate effects among Mexican smokers. Tob Control. 2013;22(e1):e57-65.

9. Siahpush M, McNeill A, Hammond D, Fong G. Socioeconomic and country variations in knowledge of health risks of tobacco smoking and toxic constituents of smoke: results from the 2002 international tobacco control (ITC) four country survey. Tob Control. 2006;15(suppl 3):iii65-70.
10. Israel Ministry of Health: The Health Minister's Report to the Knesset on Smoking 2014. Jerusalem 2015.

11. Israel Ministry of Health: Health Minister's Report to the Knesset on Smoking 2017. Jerusalem 2018.

12. Harel Y, Ezrachi Y. Use of psychoactive substances among youth in Israel 2016. Jerusalem: National Epidemiological Research Authority for the War on Drugs and Alcohol; 2017.

13. Rosen L, Peled-Raz M. Tobacco policy in Israel: 1948-2014 and beyond. Isr J Health Policy Res. 2015;4:12. Published 2015 May 1. https://doi.org/10.1186/ s13584-015-0007-x. https://ijhpr.biomedcentral.com/articles/10.1186/s13584015-0007-x

14. Rosen LJ, Rier DA, Schwartz R, Oren A, Kopel A, Gevman A, et al. Public support for smoke-free areas in Israel: a case for action. Health Policy. 2012;106(2):161-8.

15. Rosen L, Rier D, Connolly G, Oren A, Landau C, Schwartz R, et al. Do health policy advisors know what the public wants? An empirical comparison of how health policy advisors assess public preferences regarding smoke-free air, and what the public actually prefers. Isr J Health Policy Res. 2013;2:20.

16. Danishevski K, Gilmore A, McKee M. Public attitudes towards smoking and tobacco control policy in Russia. Tob Control. 2008;17:276-83.

17. Brewer NT, Chapman GB, Gibbons FX, Gerrard M, McCoul KD, Weinstein ND. Meta-analysis of the relationship between risk perception and health behavior: the example of vaccination. Health Psychol. 2007;26(2):136-45.

18. Rosen $\sqcup$, Kostjukovsky I. Parental risk perceptions of child exposure to tobacco smoke. BMC Public Health. 2015;15:90.

19. Rosenstock IM. Historical origins of the health belief model. Health Educ Monogr. 1974;2(4):328-35.

20. Israel Ministry of Health: Report of the Health Minister on Smoking in Israel 2010 Jerusalem, 2011.

21. Ginsberg GM, Geva $H$. The burden of smoking in Israel-attributable mortality and costs (2014). Isr J Health Policy Res. 2014;3(1):28.

22. OECD. International traffic safety data and analysis group. Road Safety Annual Report. 2015;2015.

23. Agaku IT, Filippidis FT. Prevalence, determinants and impact of unawareness about the health consequences of tobacco use among 17,929 school personnel in 29 African countries. BMJ Open. 2014;4(8):e005837.

24. Fakir SE, Serhier Z, Berraho M, Elrhazi K, Tachfouti N, Slama K, et al. Knowledge and perceptions of smoking according to income level in Morocco. Am J Health Promot. 2011;25(6):387-91.

25. Gupta B, Kumar N. A cross-country comparison of knowledge, attitudes, and practices about tobacco use: findings from the global adult tobacco survey. Asian Pac J Cancer Prev. 2014;15(1512):5035-42.

26. Yang J, Hammond D, Driezen P, Fong GT, Jiang Y. Health knowledge and perception of risks among Chinese smokers and non-smokers: findings from the wave 1 ITC China survey. Tob Control. 2010;21(12):24-9.

27. Hammond D, Fong GT, McNeill A, Borland R, Cummings KM. Effectiveness of cigarette warning labels in informing smokers about the risks of smoking: findings from the international tobacco control (ITC) four country survey. Tob Control. 2006;15(suppl 3):iii19-25.

28. Abdullah AS, Driezen P, Sansone G, Nargis N, Hussain GA, Quah AC, et al. Correlates of exposure to secondhand smoke (SHS) at home among nonsmoking adults in Bangladesh: findings from the ITC Bangladesh survey. BMC Pulm Med. 2014;14(1):117.

29. Sansone GC, Raute LJ, Fong GT, Pednekar MS, Quah AC, Bansal-Travers M, et al. Knowledge of health effects and intentions to quit among smokers in India: findings from the tobacco control policy (TCP) India pilot survey. Int J Environ Res Public Health. 2012;9(2):564-78.

30. Weinstein N. Accuracy of smokers' risk perceptions. Ann Behav Med. 1998; 20(2):135-40.

31. Brownson RC, Jackson-Thompson J, Wilkerson JC, Davis JR, Owens NW, Fisher EB Jr. Demographic and socioeconomic differences in beliefs about the health effects of smoking. Am J Public Health. 1992;82(1):99-103.

32. Driezen P, Abdullah AS, Nargis N, Hussain A, Fong GT, Thompson ME, et al. Awareness of tobacco-related health harms among vulnerable populations in Bangladesh: findings from the international tobacco control (ITC) Bangladesh survey. Int J Environ Res Public Health. 2016;13(9):848.

33. Minh An DT, Van Minh H, Huong LT, Bao Giang K, Thanh Xuan LT, Thi Hai P, et al. Knowledge of the health consequences of tobacco smoking: a crosssectional survey of Vietnamese adults. Glob Health Action. 2013;6(1):18707.

34. Wang TW, Asman K, Gentzke AS, Cullen KA, Holder-Hayes E, Reyes-Guzman C, et al. Tobacco product use among adults_United States, 2017. Morb Mortal Wkly Rep. 2018;67(44):1225. 
35. Reid JL, Hammond D, Rynard VL, Madill CL. R. B: tobacco use in Canada: patterns and trends, 2017. Waterloo: Population Centre for population health impact: University of Waterloo; 2017.

36. Physicians TAGotRCo. Nicotine without smoke-tobacco harm reduction. London: Royal College of Physicians; 2016. https://www.rcplondon.ac.uk/ projects/outputs/nicotine-without-smoke-tobacco-harm-reduction-0.

37. Gilmore AB, Tavakoly B, Hiscock R, Taylor G. Smoking patterns in Great Britain: the rise of cheap cigarette brands and roll your own (RYO) tobacco. J Public Health. 2015;37(1):78-88.

38. Baron-Epel O, Haviv-Messika A. Factors associated with age of smoking initiation in adult populations from different ethnic backgrounds. Eur J Pub Health. 2004;14(3):301-5.

39. Farrelly MC, Nonnemaker J, Davis KC, Hussin A. The influence of the national truth ${ }^{\odot}$ campaign on smoking initiation. Am J Prev Med. 2009;36(5):379-84.

40. Costello MJ, Logel C, Fong GT, Zanna MP, McDonald PW. Perceived risk and quitting behaviors: results from the ITC 4-country survey. Am J Health Behav. 2012;36(5):681-92.

41. Hons AMMB. The response of young adult smokers and nonsmokers in the United Kingdom to dissuasive cigarettes: An online survey. Nicotine Tob Res. 2017:1:7.

42. Moodie C, MacKintosh AM, Gallopel-Morvan K, Hastings G, Ford A. Adolescents' perceptions of an on-cigarette health warning. Nicotine Tob Res. 2016;19(10):1232-7.

43. Malone RE. Conflicts and controversies in contemporary tobacco control: BMJ Publishing Group Ltd. Tobacco Control. 2017;26:e1-e2.

44. Rosen L, Kislev S. The IQOS campaign in Israel. Tob Control. 2018:0:1-4.

45. Kopel E, Davidovitch N, Levine H. Using all means to protect public health in Israel from emerging tobacco products. Am J Public Health. 2017;107: 1599-600.

46. Kaufman AR, Persoskie A, Twesten J, Bromberg J. A review of risk perception measurement in tobacco control research. Tobacco Control. 2018:0:1-9. https://doi.org/10.1136/tobaccocontrol-2017-054005.

47. Krosnick JA, Berent MK. Comparisons of party identification and policy preferences: the impact of survey question format. Am J Polit Sci. 1993:941-64.

48. Huerta M, Chodick G, Balicer RD, Davidovitch N, Grotto I. Reliability of selfreported smoking history and age at initial tobacco use. Prev Med. 2005; 41(2):646-50.

49. Luepker RV, Pallonen UE, Murray DM, Pirie PL. Validity of telephone surveys in assessing cigarette smoking in young adults. Am J Public Health. 1989; 79(2):202-4

Ready to submit your research? Choose BMC and benefit from:

- fast, convenient online submission

- thorough peer review by experienced researchers in your field

- rapid publication on acceptance

- support for research data, including large and complex data types

- gold Open Access which fosters wider collaboration and increased citations

- maximum visibility for your research: over $100 \mathrm{M}$ website views per year

At BMC, research is always in progress.

Learn more biomedcentral.com/submissions 